\title{
Supplementary Information on
}

\section{"Selective Dissolution Resistance Control of EUV Photoresist using Multiscale Simulation: Rational Design of Hybrid System"}

Muyoung Kim ${ }^{1,2}$, Junghwan Moon ${ }^{1,2}$, Sungwoo Park ${ }^{2}$, and Maenghyo Cho ${ }^{1,2, *}$

${ }^{1}$ Institute of Advanced Machines and Design, Seoul National University, Seoul, Republic of Korea

2 Division of Multiscale Mechanical Design, School of Mechanical and Aerospace Engineering, Seoul National University, Seoul, Republic of Korea 


\section{- A detailed analysis of the acid migration in the KMC lattice model}

For further understanding on acid migration in Figure 3c, we derived the probability distribution of the KMC walking distance (Figure S3a-S3d) that was collected from the penetrant transition path at each iteration step. The acid trajectories exhibited the walking distance in the range of $0.25-4.25 \AA$ for localization and $3.75-8.25 \AA$ for hopping. The presented KMC walking distance covered only $1.1-1.3 \%$ of the spatial gap $\left(r_{\text {cavitiy }}\right)$ between the different cavities, which was examined by gauging the distance among the centroids of all identified acidaccessible free volumes in Figure S3e-S3h. Although acid hopping showed a much lower probability density peak $\left(0.007-0.039 \AA^{-1}\right)$ for the KMC walking distance compared to that of localization $\left(0.186-0.629 \AA^{-1}\right)$, the occasional hopping distance comprised a dominant proportion (94.3-97.4\%) of $r_{\text {cavity }}$ within the feasible range of the KMC walk. In other words, under the identical protection ratio of the PR chain (similar trap zone volume), physical properties relevant to hopping, such as distance criteria and probability weighting factor ( $R_{\text {hop.min }}-R_{\text {hop.max }}$ and $w_{\text {hop }}$ in Section 2.2$)$ would be critical design parameters for tailored acid diffusivity.

Additionally, during the penetrant migration by localization and hopping, the acid molecule walked into the trap zone (4.12 Å radius from single tBOCSt group, see Figure $3 a)$ approximately $31.8-41.1 \%$ of the iteration steps, originating from the considerable occupation ratio (39.3-43.1\%) of the trap zone in the unit cell. In each trapped $\mathrm{KMC}$ step, the penetrant migration was temporarily delayed by the deprotection time $\left(\Delta t_{\text {trap }}: 3 \mathrm{~ms}\right.$, algorithm I-ix in Section 2.2). Such retardation in the trap zone extended the diffusion time from ps- (observable range in MD simulation) to ms-scale, which was not achievable through classical MD studies, leading to a quantitatively accurate prediction on acid diffusivity in Table 2. 


\section{- Derivation of the repulsion parameter in the DPD force-field}

Groot and Warren's theory ${ }^{[S 1]}$, which linked the Flory-Huggins $\chi$-parameter to the solubility $(\delta)$ and mixing energy $\left(\Delta E_{m i x}\right)$ of the molecular components, was adopted to obtain the repulsive coefficient ( $a_{i j}$ in Eq. 11). The cohesive energy $\left(E_{c o h}\right)$ is a key property for the theory and was calculated from ab initio molecular dynamics (AIMD) using the Vienna ab initio simulation package ${ }^{[\mathrm{S2}, \mathrm{S} 3]}$ (VASP) based on DFT. We applied the projector augmented wave $(\mathrm{PAW})$ method $^{[\mathrm{S4}, \mathrm{S5}]}$ with a plane-wave basis set having the cutoff energy of $750 \mathrm{eV}$. The Brillouin zone was sampled only at the $\Gamma$-point for the computational efficiency of the AIMD calculation. Both the generalized gradient approximation (GGA) with the Perdew-Burke-Ernzerhof ${ }^{[\mathrm{S6}, \mathrm{S} 7]}$ (PBE) and optB88$\mathrm{vdW}^{[88]}$ functional, which are suitable for describing the electronic structure of organic material ${ }^{[\mathrm{S9}, \mathrm{S10]}}$ and liquid water, ${ }^{[S 11]}$ respectively, were applied to the neat polymeric pendant group and water-incorporated system, respectively.

The initial amorphous unit cells $(1.36 \times 1.36 \times 1.36 \mathrm{~nm})$, which were composed of HOSt (bead S), tBOCSt (bead I), water (bead W), and their mixtures, were constructed using the Theodorou-Suter method ${ }^{[S 12]}$ implemented in the Material Studio 2016 package, and geometry optimization was performed for both internal atomic configuration and unit cell volume (see detailed information in Figure S9 and Table S2). Then, the NVT ensemble based on Born-Oppenheimer molecular dynamics was applied with a time step of 1.0 fs for 10-20 ps at $300 \mathrm{~K}$, and the temperature was controlled by Nose-Hoover thermostat.

Based on the fully equilibrated AIMD unit cell, the single-point-energy calculation was performed to obtain the energy of isolated constituent molecules $\left(E_{\text {molecule. }}, n=1-N_{\text {molecule }}\right)$ and bulk system $\left(E_{\text {bulk }}\right)$ in Eq. S1. The vdWDF2 exchange-correlation function ${ }^{[S 13]}$ was employed for the single point energy, which was determined by comparing the solubility of HOSt and water from various energy functional with the experimental value (see Table S3).

$$
E_{\text {coh }}=\frac{\left(\Sigma_{n=1}^{N_{\text {molecule }}} E_{\text {molecule. } n}\right)-E_{\text {bulk }}}{N_{\text {molecule }}}
$$

The derived cohesive energy $\left(E_{c o h}\right)$ was applied to calculate the solubility ( $\delta$ in Eq. S2) and $\chi$-parameter (Eq. S3) in turn. The variables in Eq. S2 and S3 are the molar volume of the AIMD unit cell $V_{m}$, volume of the CG bead $V_{\text {bead }}\left(510-552 \AA^{3}\right)$, Boltzmann constant $k_{B}$, and temperature $T$. 


$$
\chi_{i j}= \begin{cases}\delta=\sqrt{\frac{E_{c o h}}{V_{m}}} \\ \frac{V_{\text {bead }}\left(\delta_{i}-\delta_{j}\right)^{2},}{} & i \in \text { bead S and } j \in \text { bead I } \\ \frac{V_{\text {bead }}}{k_{B} T}\left(\Delta E_{\text {mix }}\right), & i \in \text { bead } \mathrm{W} \text { and } j \in \text { bead } \mathrm{S}, \mathrm{I}\end{cases}
$$

The Flory-Huggins parameter $\chi_{i j}$ for polymer-polymer interactions $(i, j$ : bead $\mathrm{S}$ and $\mathrm{I})$ was simply calculated by the solubility difference $\left(\delta_{i}-\delta_{j}\right)$ between species $i$ and $j$, which has been widely accepted for determining the miscibility of a binary system ${ }^{[\mathrm{S} 14, \mathrm{~S} 15]}$ in the absence of a predominant specific interaction, such as hydrogen bond and non-combinatorial entropy effect. To estimate the interaction between the solvent ( $i$ : bead $\mathrm{W})$ and polymeric pendant bead $(j$ : bead $\mathrm{S}$ and $\mathrm{I})$, the $\chi_{i j}$ parameter was obtained from the mixing energy $\left(\Delta E_{m i x}\right.$ in Eq. S4), which is suitable for a polymer-aqueous solution blend system. ${ }^{[\mathrm{S} 16, \mathrm{~S} 17]}$ Mixing energy $\Delta E_{\operatorname{mix}}$ indicates the cohesive energy density change between the pure (subscript $i$ and $j$ ) and blended system (subscript $i j$ ).

$$
\Delta E_{m i x}=\phi_{i}\left(\frac{E_{c o h}}{V_{m}}\right)_{i}+\phi_{j}\left(\frac{E_{c o h}}{V_{m}}\right)_{j}-\left(\frac{E_{c o h}}{V_{m}}\right)_{i j}
$$

Here, $\phi_{i}$ and $\phi_{j}$ are the volume fractions of the two CG bead constituents in the binary system. Then, the repulsion parameter $a_{i j}$ between two different beads was derived from the Flory-Huggins parameter in Eq. S5 under a dimensionless bead density ${ }^{[\mathrm{S} 1]} \bar{\rho}=3$. To attain the compressibility of water in the bead density $(\bar{\rho}=3)$, the repulsive parameter between the same beads was set to the value of $a_{i i}=25 .{ }^{\text {[S1] }}$

$$
a_{i j}=a_{i i}+\frac{\chi_{i j}}{0.286}
$$




\section{- A detailed analysis of the polymer-solvent mixing process in the DPD simulation}

In the development process, the polar solvent wipes out the deprotected chains of the positive-tone CAR, whereas the residual ones form the line pattern. Figure S12a and S12b (see the movie clip on Video S2) show sequential snapshots of the DPD cell during the development process and the concentration profile along the permeation direction for a representative model ( $\mathrm{PR} M_{n}: 2.8 \mathrm{~kg} / \mathrm{mol}$, developer: water, temperature: $\left.300 \mathrm{~K}\right)$. At the early stages $\left(0-4 \times 10^{4} \tau\right)$, polymer chains in the hydrophilic buffer and exposed PR domain (tBOCSt:HOSt molar ratio $\sim 1: 24$ ) preferentially penetrate into the solvent layer by $12.2 \mathrm{~nm}$ thickness while unexposed PR (tBOCSt:HOSt molar ratio 1:2) and hydrophobic buffer chains keep their initial position. The proportion of HOSt groups in a single copolymer chain substantially governs the miscibility of polymer against the developer, which originates from the strong hydrogen bond network of the HOSt-water mixture as opposed to tBOCStwater blend system (Figure $5 \mathrm{~b}$ and $5 \mathrm{c}$ ).

After permeation, large numbers $(87.6 \mathrm{~mol} \%)$ of irradiated PR chains infiltrating across the interface are dissolved by the surrounding water beads, which exceed the solvation criteria (see Figure S10). To fill up the empty spaces behind the chain migration, the water beads flow into the polymer layer by $5.0 \mathrm{~nm}$ and partly hydrate the remaining chains, leading to a solvation of masked PR chains of $12.9 \mathrm{~mol} \%$.

As the development time elapses $\left(4 \times 10^{4}-12 \times 10^{4} \tau\right)$, the water-polymer interface continuously grows to the width of $35.3 \mathrm{~nm}$; thus, the solvation is progressed for both exposed- $(87.6 \rightarrow 95.9 \mathrm{~mol} \%)$ and masked PR chains $(12.9 \rightarrow 51.6 \mathrm{~mol} \%)$ located within the interfacial zone. In the latter half of the DPD simulation $\left(12 \times 10^{4} \tau\right)$, a clustered structure of polymer chains is found in which the hydrophobic beads agglomerate into the core part, and the hydrophilic ones constitute a spherical shell contacting with the surrounding solvent particles. 


\section{- Supplementary Figures}

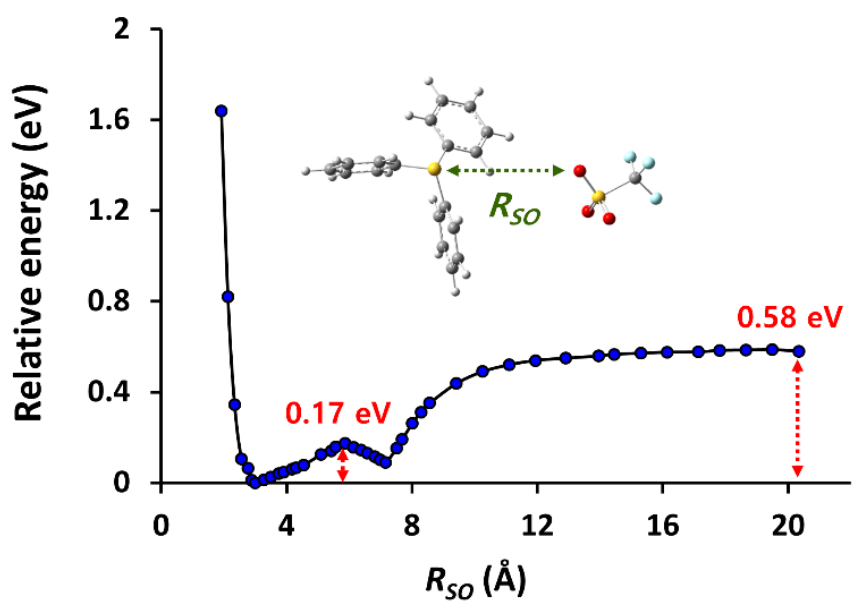

Figure S1. Dissociation energy curve ${ }^{[\mathrm{S} 18]}$ of a secondary electron attached PAG $\left(R_{s o}\right.$ : the distance between the sulfur of a triphenylsulfonium cation and the oxygen of a triflate anion).

(a)

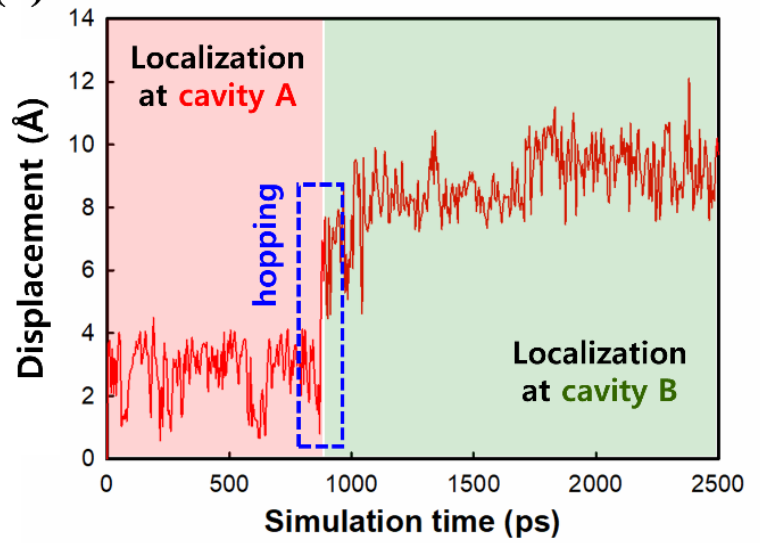

(b)

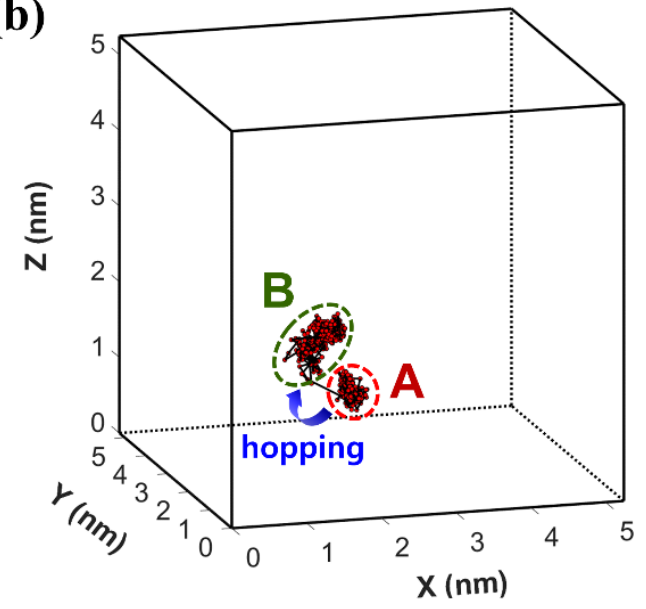

Figure S2. Acid diffusion behavior in PR matrix using MD simulation. (a) Time-evolution of molecular displacement at 500 sampled snapshots. (b) Molecular trajectories according to Figure S2a, which indicate localization at each cavity and hopping (cavity $\mathrm{A} \rightarrow \mathrm{B}$ ). 
(a)

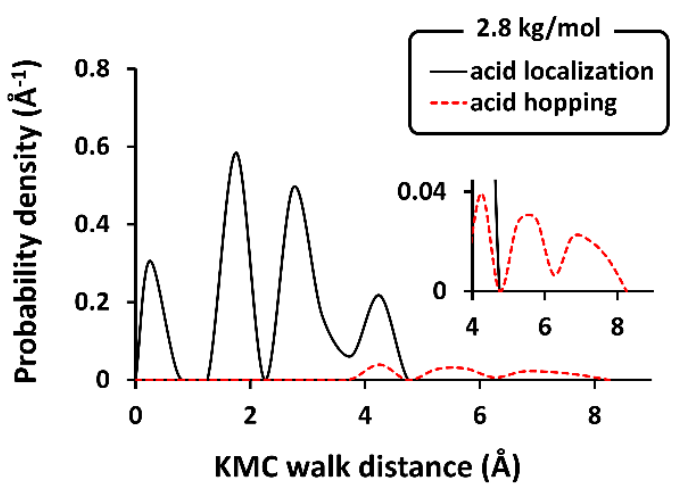

(c)

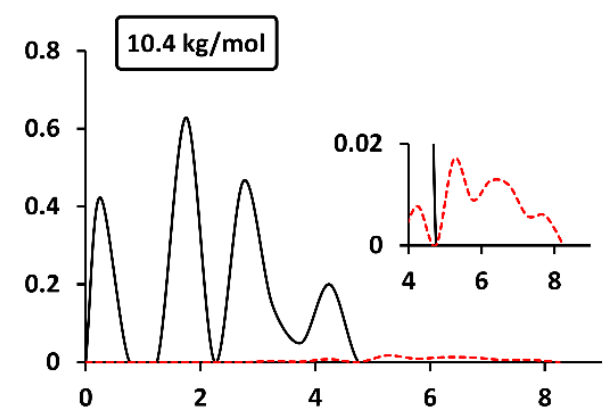

(e)

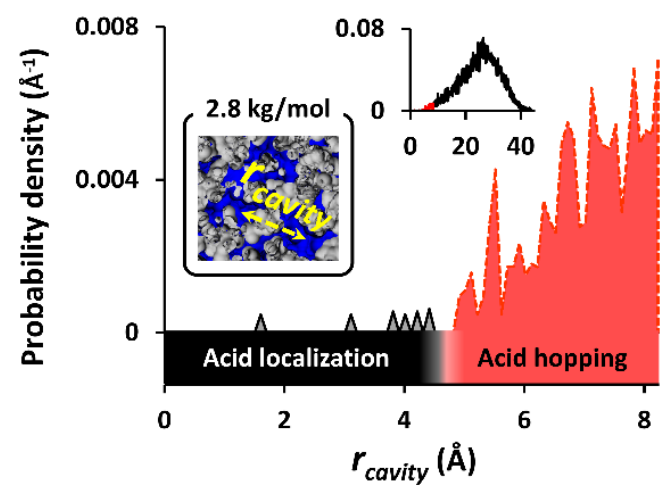

(g)

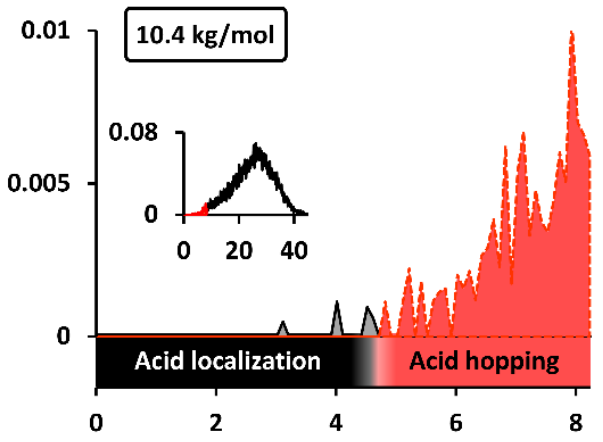

(b)

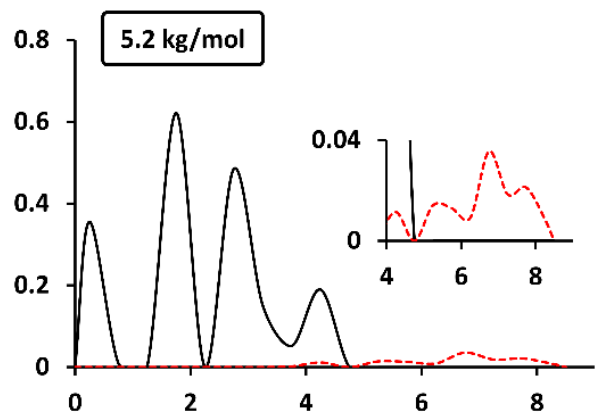

(d)

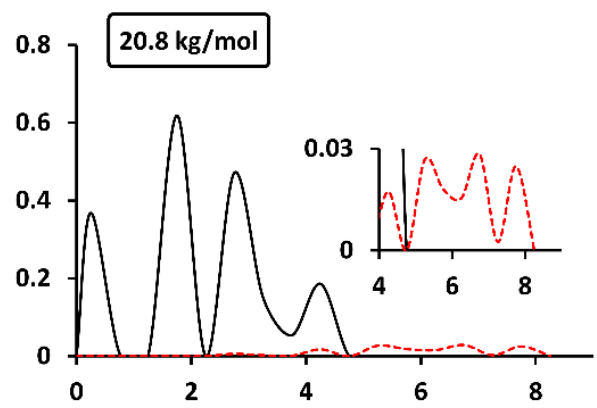

(f)

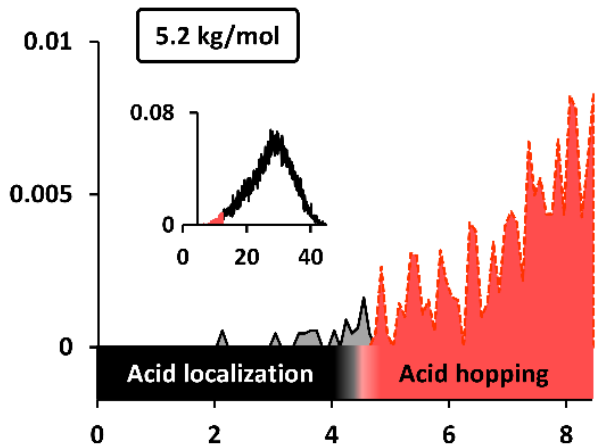

(h)

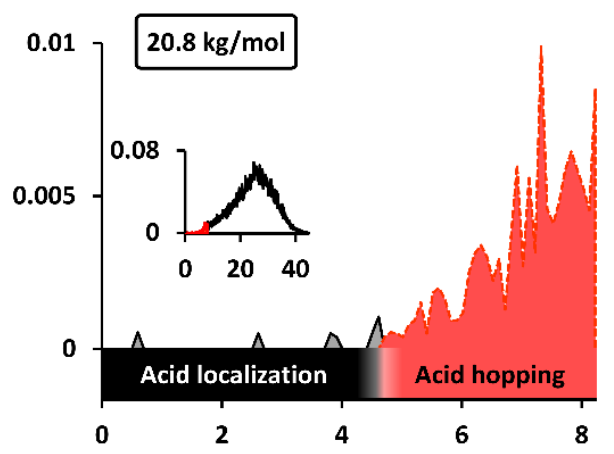

Figure S3. (a)-(d) Probability distribution of acid KMC walk distance for $2.8-20.8 \mathrm{~kg} / \mathrm{mol}$ of positive PR. (e)(h) Probability distribution of spatial gap $\left(r_{\text {cavity }}\right)$ between the acid-accessible cavities for $2.8-20.8 \mathrm{~kg} / \mathrm{mol}$ of positive PR. See supplementary section of "A detailed analysis of the acid migration in the KMC lattice model". 


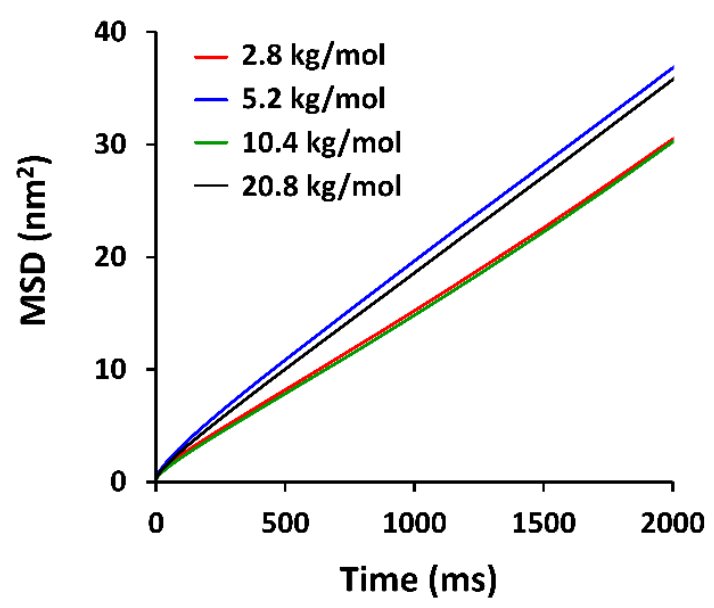

Figure S4. Mean square displacement (MSD) of photoacids in the KMC lattice model for $2.8-20.8 \mathrm{~kg} / \mathrm{mol}$ of positive PRs (see, KMC trajectories in Figure $3 \mathrm{c}$ and the consequent diffusivity in Table 2).

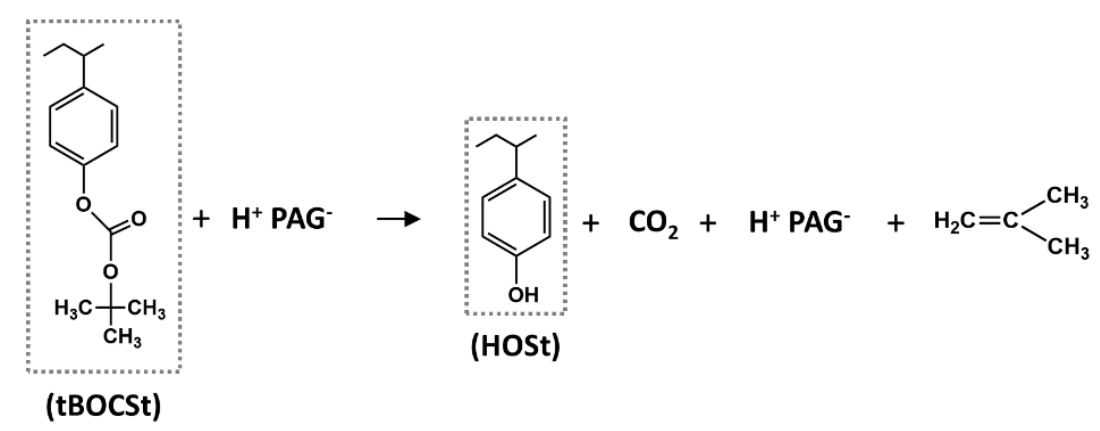

Figure S5. Deprotection reaction in poly(hydroxystyrene-co-[tert-butoxycarbonyl]oxystyrene) photoresist. $\mathrm{PAG}^{-}$represents a triflate anion. 


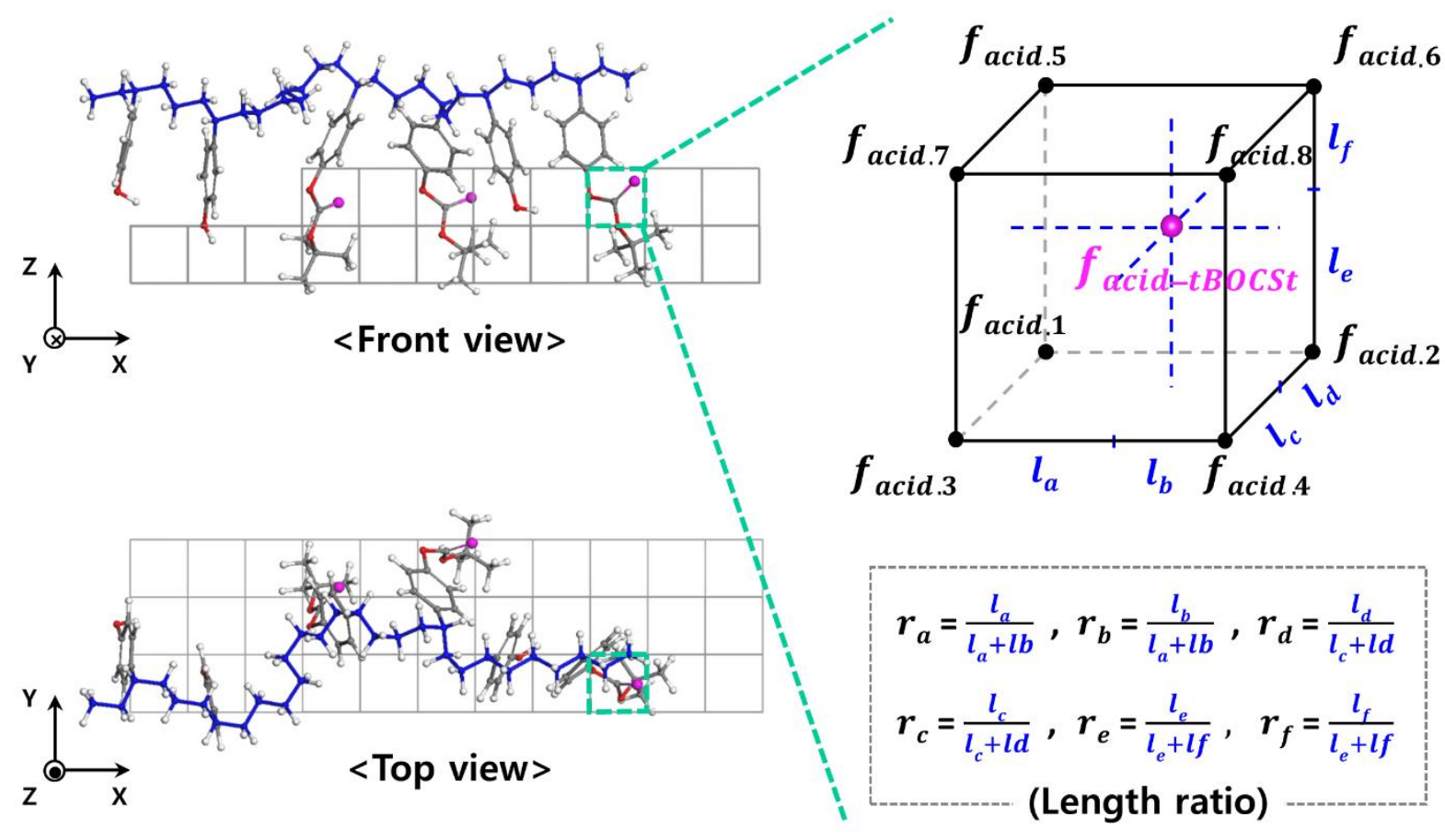

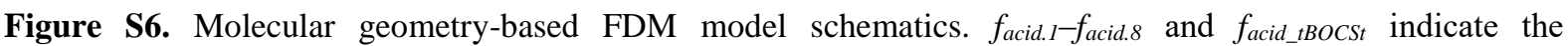
normalized local acid concentration at each node and protection group, individually. $l_{a}-l_{f}$ specify the position of the oxygen atom (pink ball) of the carbonyl of the protection group.
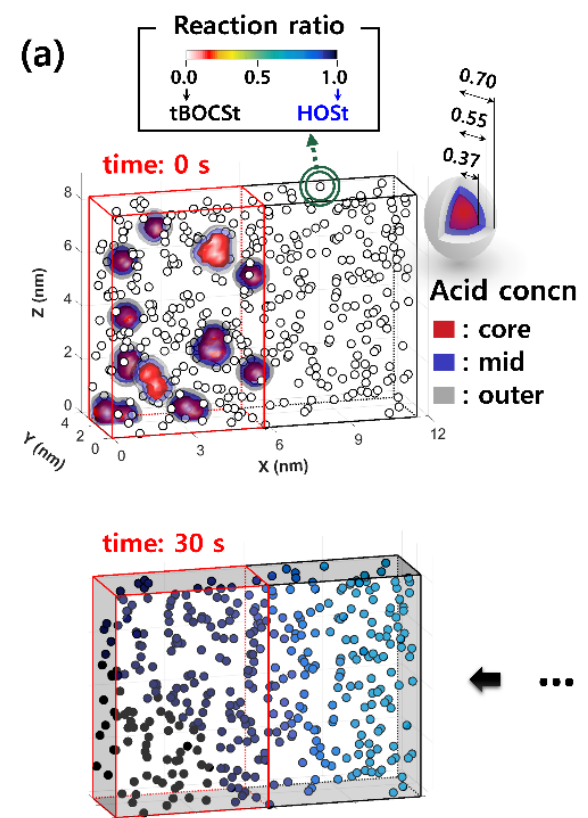
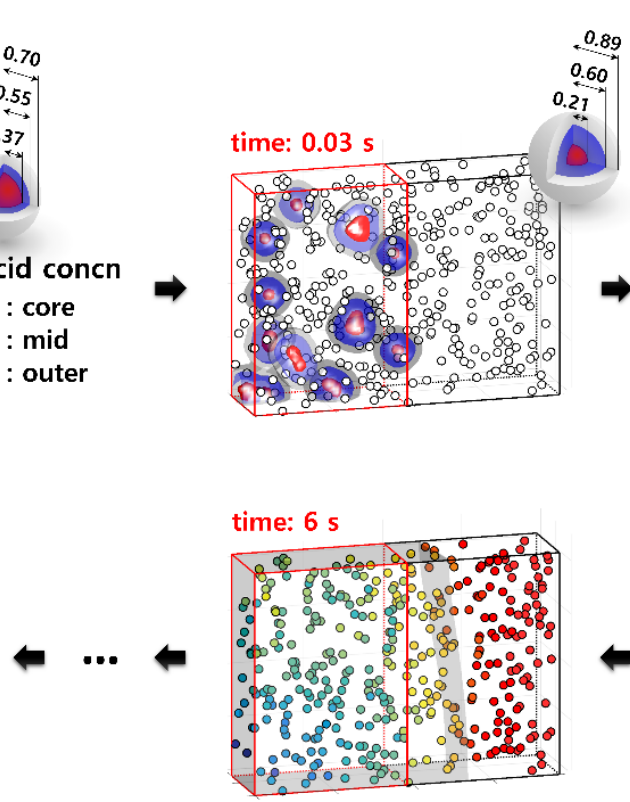

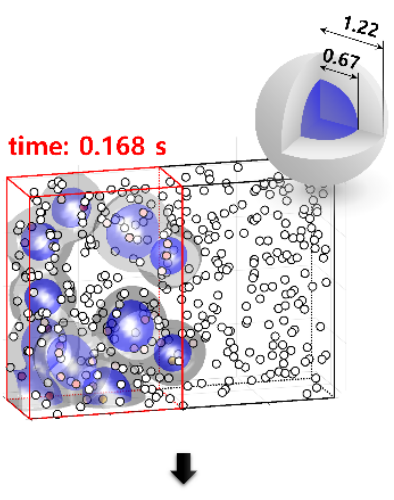

time: $1.14 \mathrm{~s}$

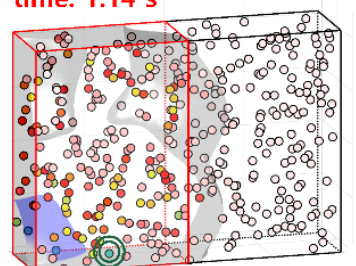

Preferential deprotection 
(b)

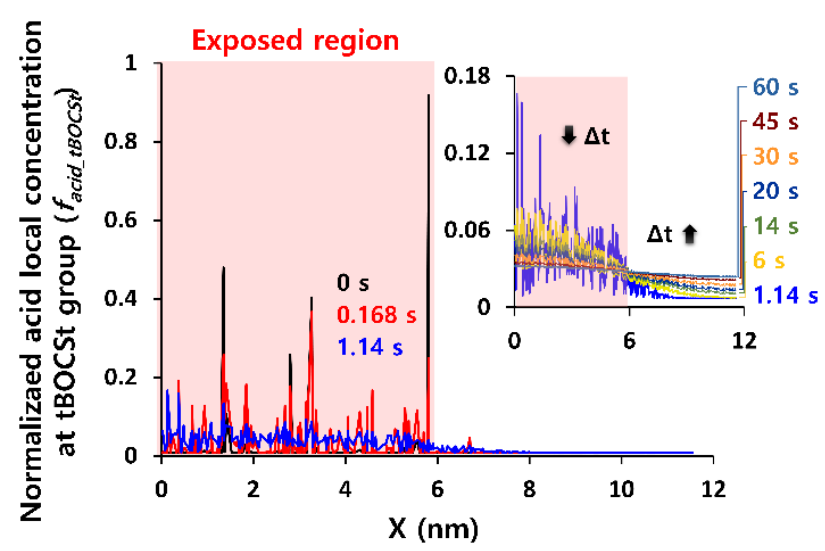

(c)

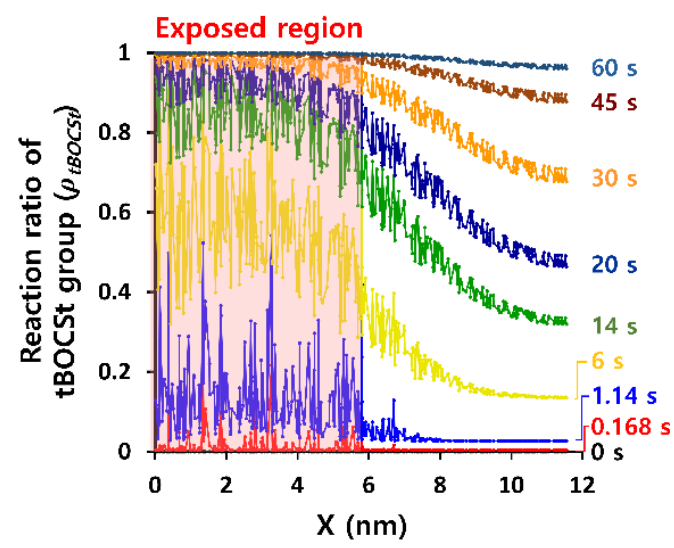

Figure S7. (a) Acid diffusion-coupled PR deprotection in the FDM unit cell. Normalized local acid concentration is indicated as isosurfaces (core: $f_{\text {acid.n }} 0.8$, mid: $f_{\text {acid.n }} 0.1$, outer: $f_{\text {acid.n }} 0.015$ ), and their spherical radii are shown in the inset in nanometers. The color change of small circles with black edges represents the reaction ratio $\left(\rho_{t B O C S t}\right)$ of individual tBOCSt group. The exposure region is marked as a red outline. (b), (c) Twodimensional graphs of acid concentration and reaction ratio corresponding to Figure S7a. Individual scattered point is plotted in terms of the $\mathrm{x}$-position of each protection group in the FDM unit cell.

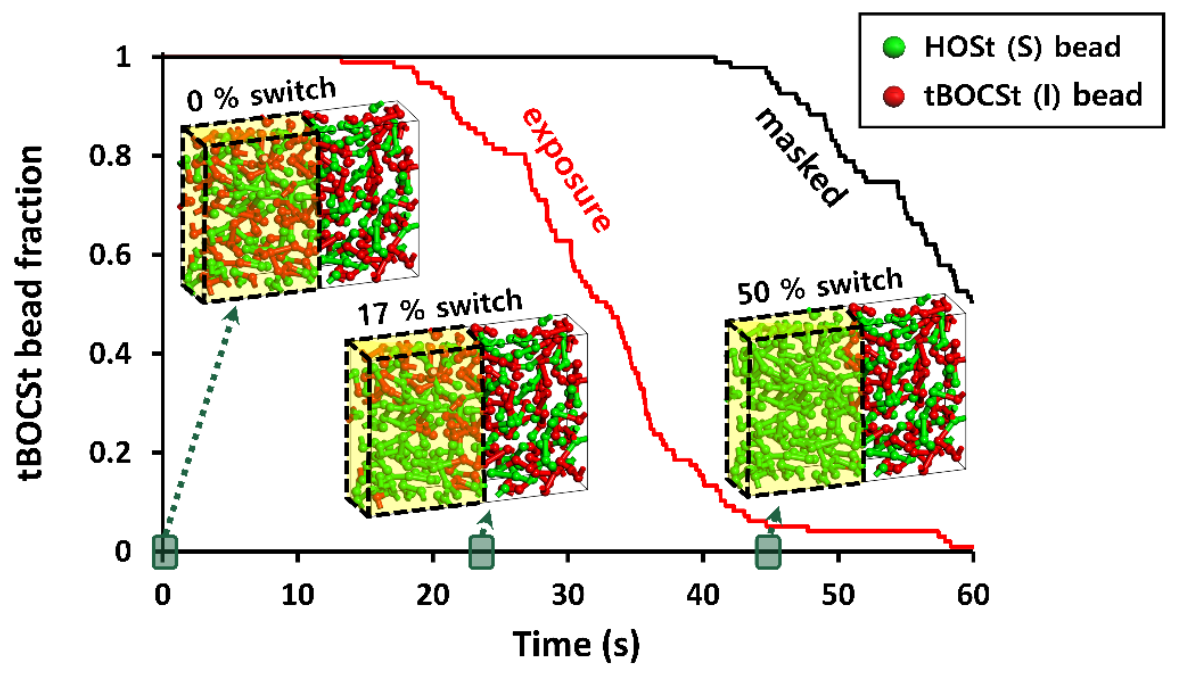

Figure S8. Bead-switch process from tBOCSts to HOSts during the PEB, based on acid diffusion-coupled deprotection simulation in Figure S7. An average reaction ratio threshold ( $\left.\rho_{t B O C S t}: 0.98\right)$ is applied for the bead conversion.. 


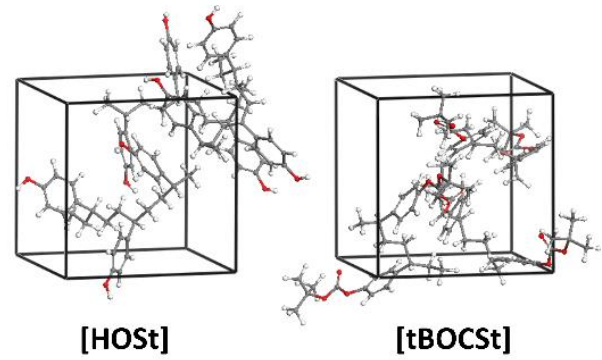

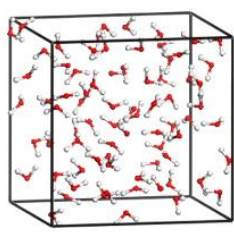

[Water]

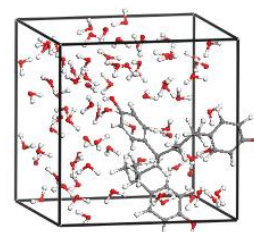

[HOSt + Water]

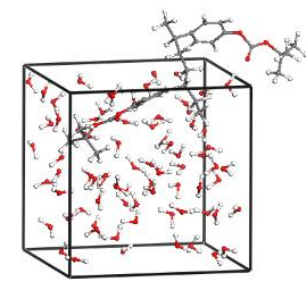

[tBOCSt + Water]

Figure S9. Atomistic configurations of pure PR, -water, and PR-water blended AIMD unit cells. A detailed information is provided in Table $\mathrm{S} 2$.
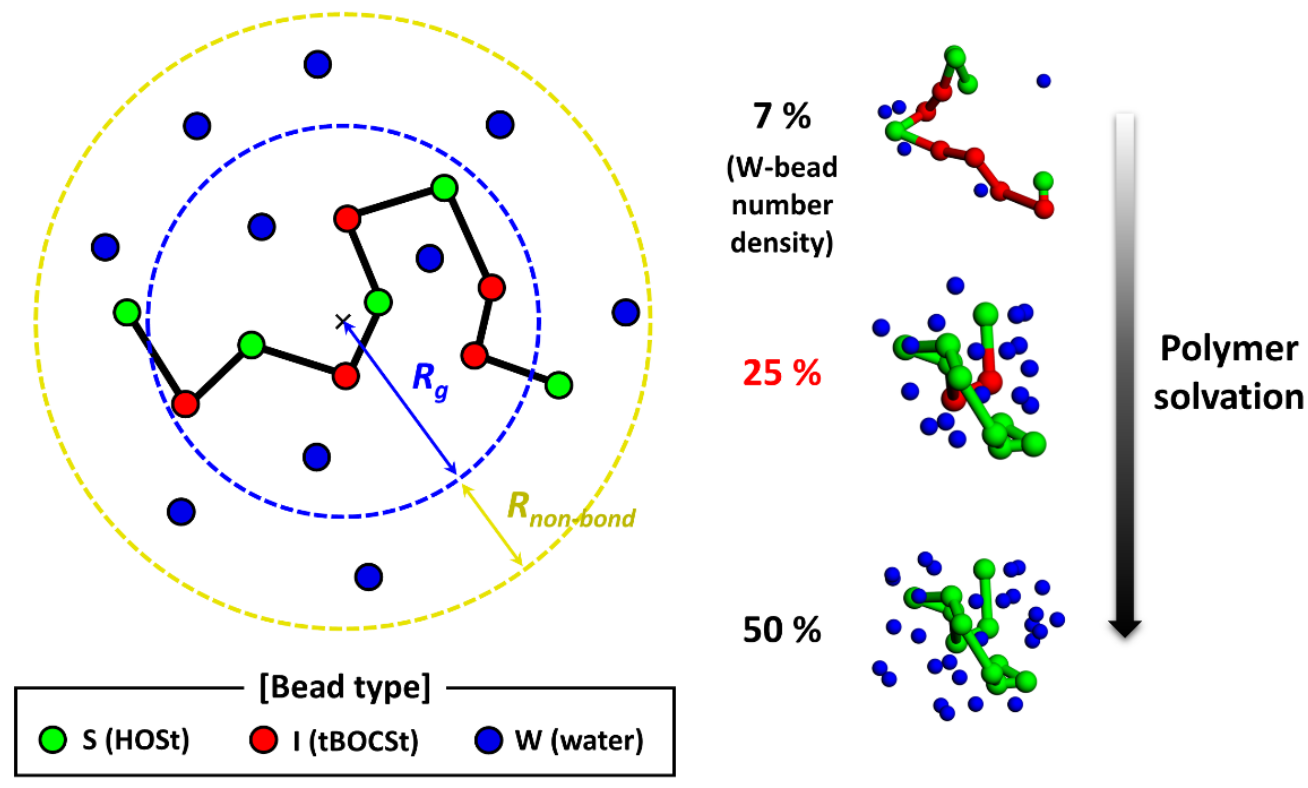

Figure S10. Solvation criterion for PR chain; the surrounding W-bead density corresponding to $25 \%$ of that of pure water, within the cutoff radius $2.1-4.1 \mathrm{~nm}$ (radius of gyration $R_{g}+$ effective non-bonded interaction distance $R_{\text {non-bond }}$ ). 

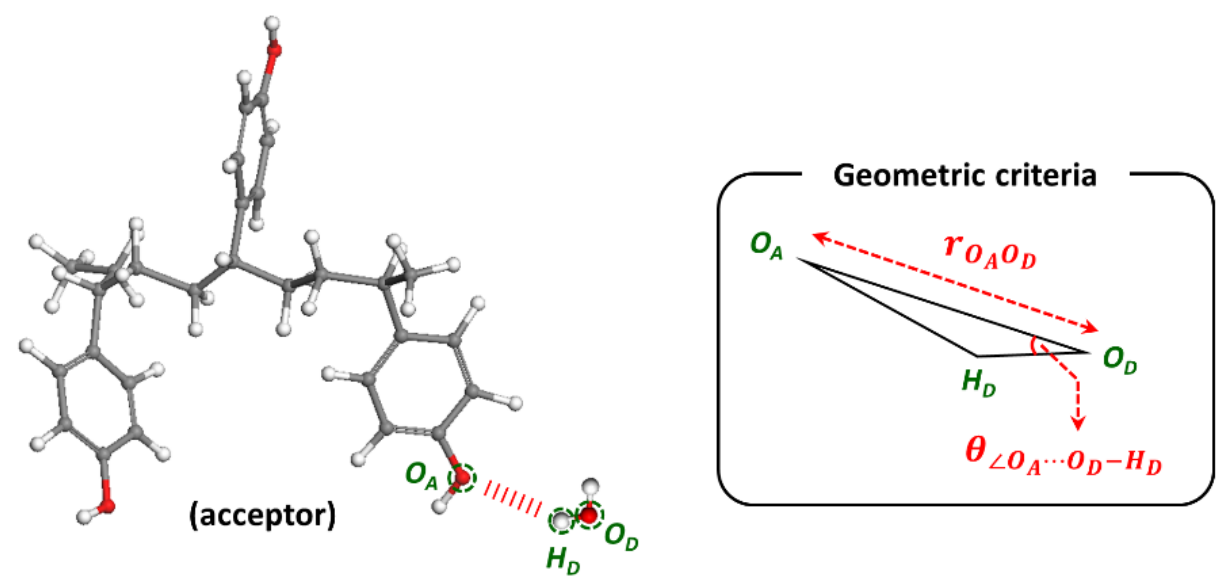

(donor)

Figure S11. Molecular geometry for identifying hydrogen bond in PR-water mixture $\left(r_{O_{A} O_{D}}<3.5 \AA\right.$ and $\left.\theta_{\angle O_{A} \cdots o_{D}-H_{D}}<30^{\circ}\right)^{[\mathrm{S} 19, \mathrm{~S} 20]}$.

(a)

W (water) $\bigcirc$ (HOSt) I (tBOCSt)
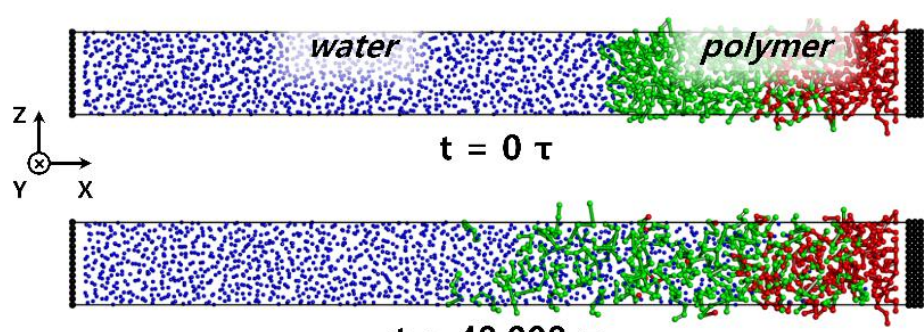

$t=40,000 \tau$

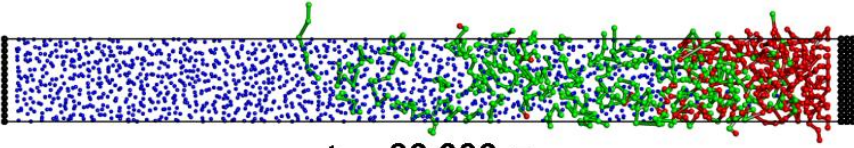

$\mathbf{t}=80,000 \tau$

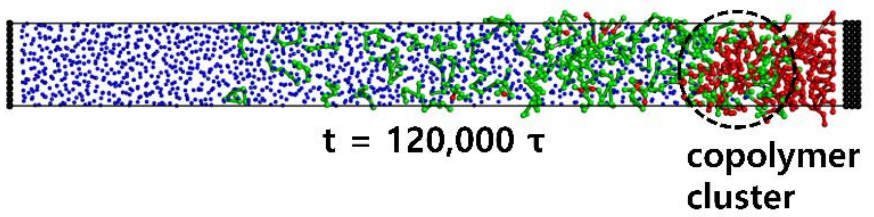




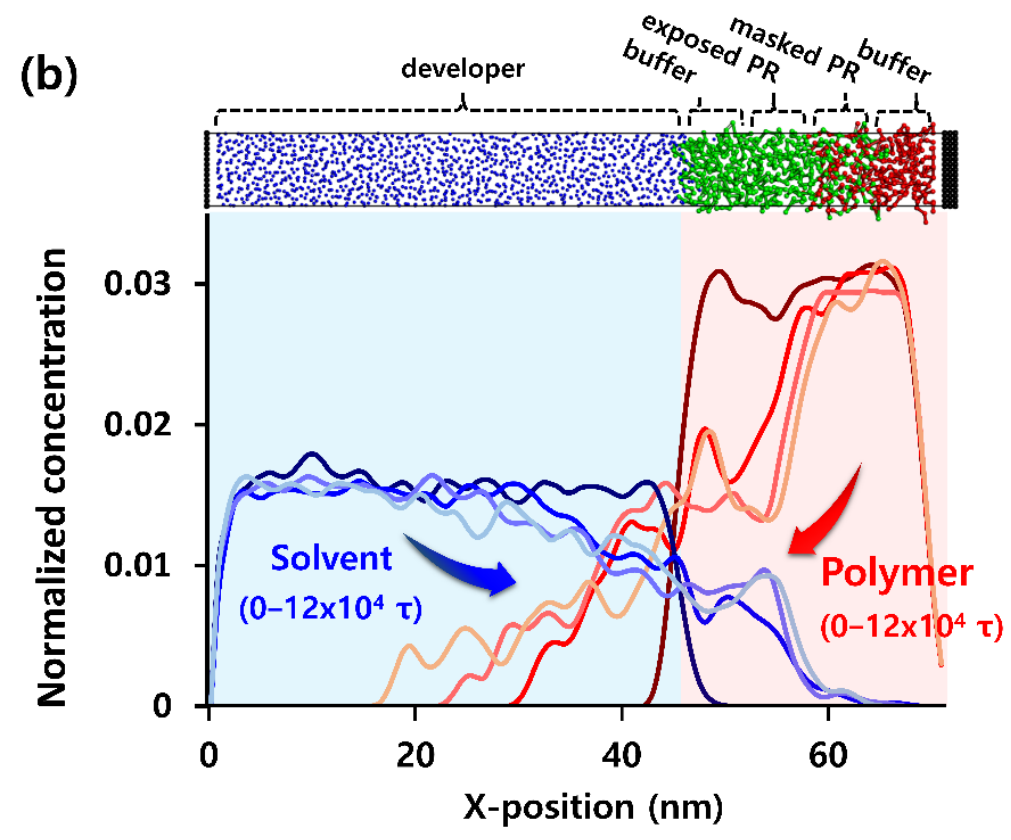

Figure S12. Time evolution of (a) the mesoscopic configurations of the polymer-water mixture and (b) the corresponding concentration profile during the development process. The concentration curve at later time data is represented as a lighter color ( $\tau$ : a reduced DPD time step of 0.01 ). See supplementary section of "A detailed analysis of the polymer-solvent mixing process in the DPD simulation".

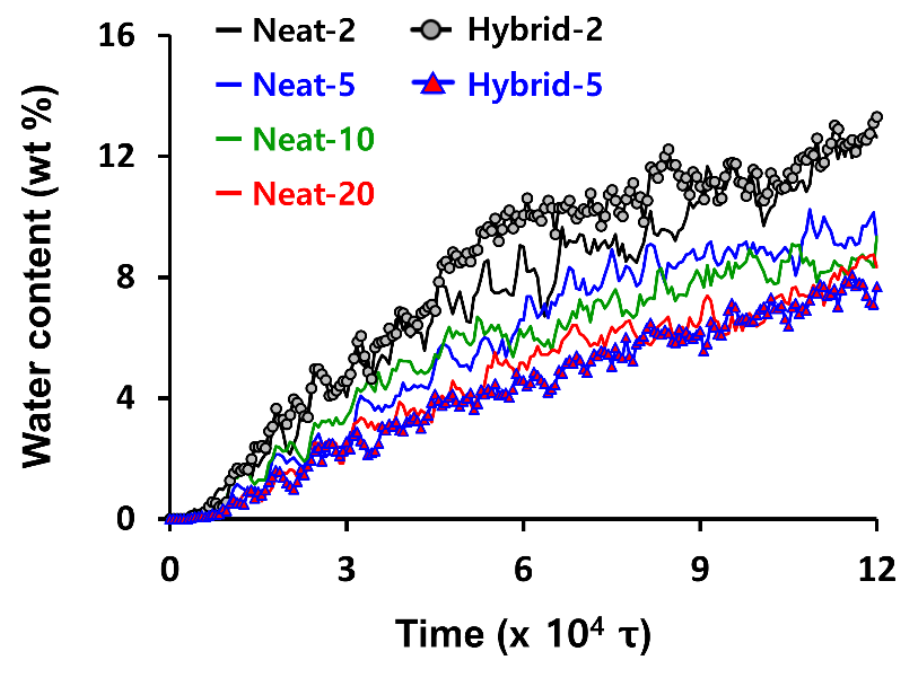

Figure S13. Time-evolutional profile of water uptake in various PR systems during the development procedure. Neat-2 to Neat-20; positive PR matrices with $2.8-20.8 \mathrm{~kg} / \mathrm{mol}$ of $M_{n}$. Hybrid-2 and Hybrid-5; hybrid PR matrices which are the products of the crosslinking reaction for Neat-2 and Neat 5 , respectively. ( $\tau$ : a reduced DPD time step of 0.01) 
(a)<smiles>CCOc1ccc(OC)cc1OCCO</smiles><smiles>OC1COC2C(O)COC12</smiles><smiles>OCC1CCCCC1</smiles>

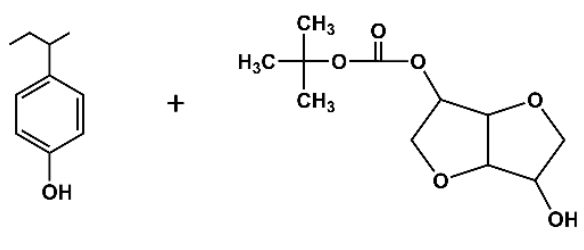<smiles>C1C[C@@H]2CO[C@@H]1CO2</smiles><smiles>CC(C)c1ccc(OC(=O)C2COC3C(O)CCC23)cc1</smiles>

(b)

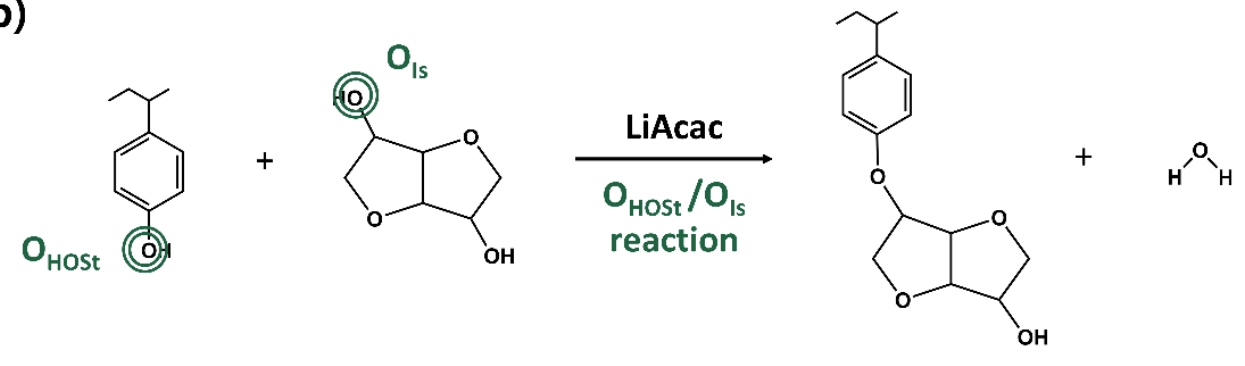

(c)

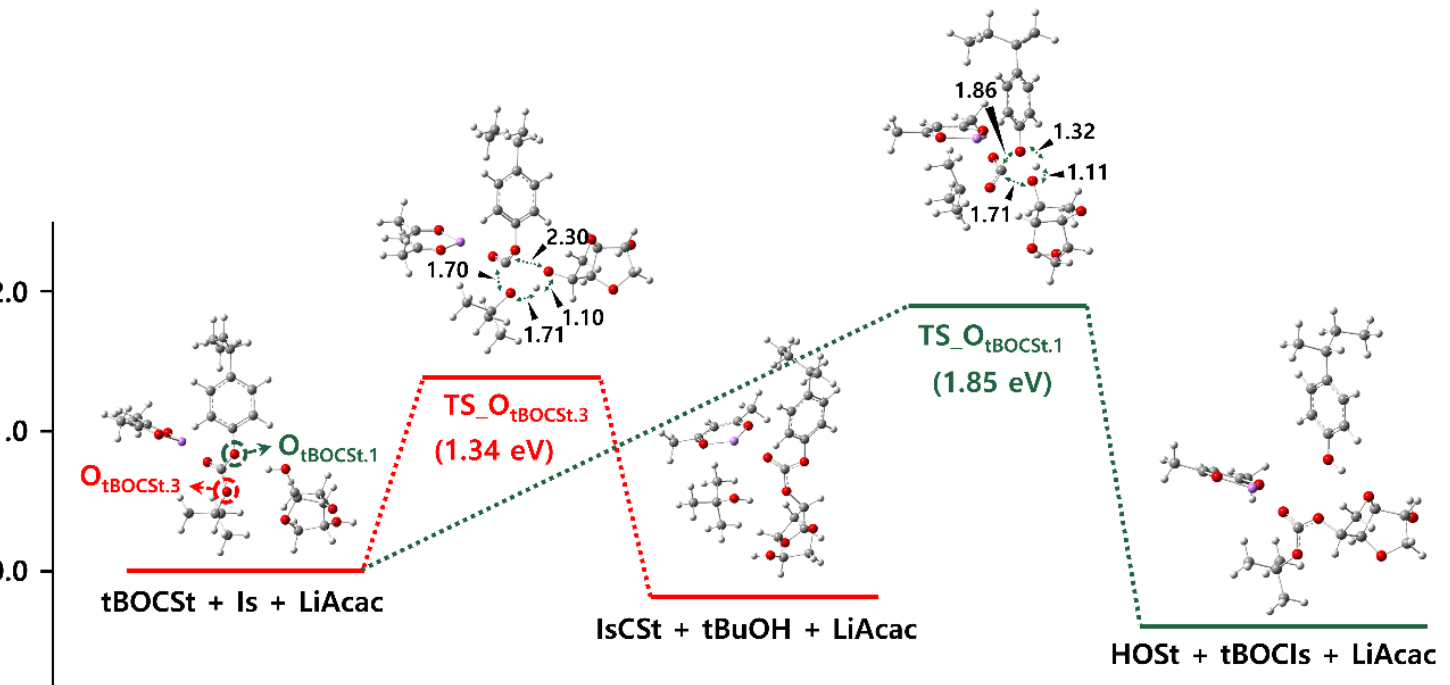

Reaction coordinate 


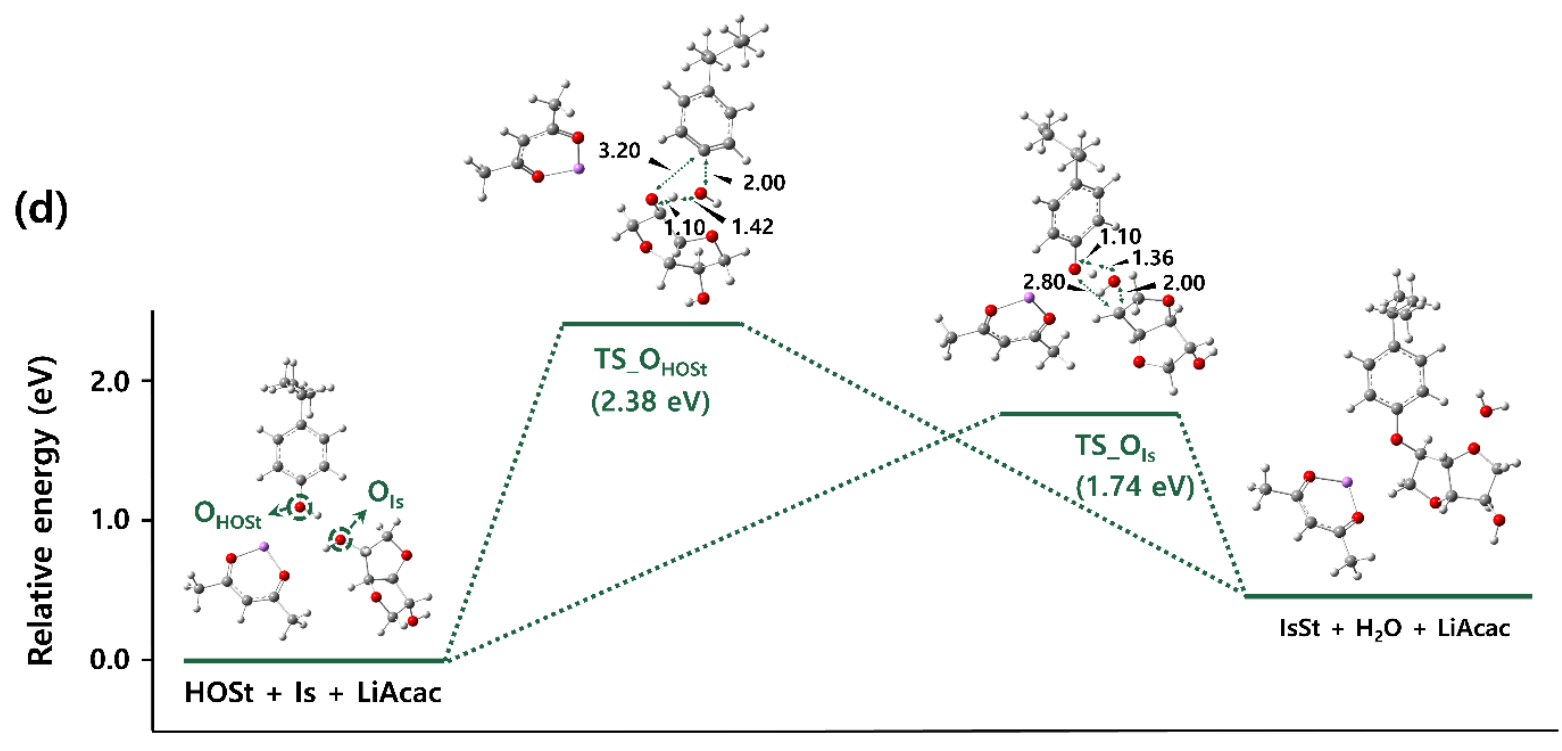

Reaction coordinate

Figure S14. (a), (b) Reaction paths between PR pendant groups and isosorbide (Is) in the presence of lithium acetylacetonate (LiAcac). (c), (d) Potential energy surface of each reaction path using DFT simulation. The distance between reactive atoms is given in the inset in angstroms. Geometry optimization (B3LYP/6$311+G(d, p))$ and single point energy calculation (APFD/6-311+G(d,p)) was carried out with the Gaussian 09 package $^{[\mathrm{S} 21]}$. Verification of the level of theory in single point energy calculation and the resulting transition state structure was given by the activation energy comparison (Table S6) and the normal mode of the imaginary frequency (Video S4-S7), respectively. (tBOCSt: tert-butoxycarbonyloxystyrene, HOSt: hydroxylstyrene, tBOCIs: tert-butoxycarbonyl isosorbide, IsCSt: isosorbide carbonyloxystyrene, tBuOH: tert-butanol, IsSt: isosorbide styrene)

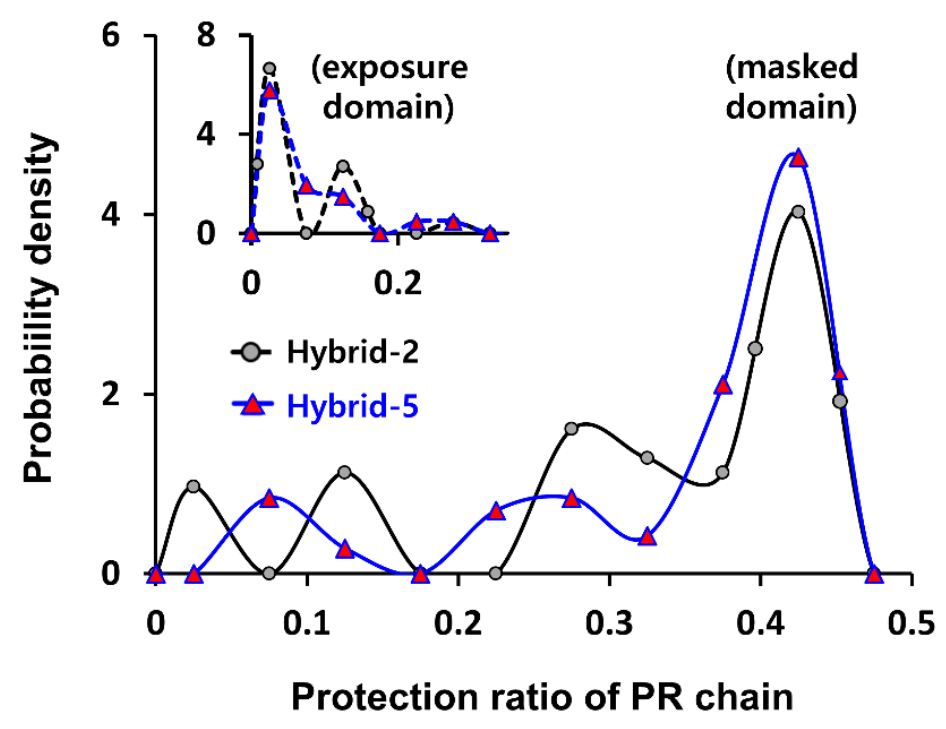

Figure S15. Probability distribution of protection ratio of PR chains for hybrid systems. Hybrid-2 and Hybrid-5; hybrid PR matrices which are the products of the crosslinking reaction for neat PR of $M_{n} 2.8$ and $5.2 \mathrm{~kg} / \mathrm{mol}$, respectively. 


\section{- Supplementary Tables}

Table S1. Adiabatic electron affinity $\left(E_{\text {neutral }}-E_{\text {anion }}\right)$ of the electron attachable sites in $\mathrm{P}(\mathrm{HOSt}$-co-tBOCSt $)$ resist blended with PAG. DFT simulation was applied with Gaussian 09 package ${ }^{[\mathrm{S21]}}$ (level of theory: B3LYP/6$311+\mathrm{G}(\mathrm{d}, \mathrm{p}))$. Geometry optimization was performed to extract the equilibrated energies of neutral- $\left(E_{\text {neutral }}\right)$ and anion molecule $\left(E_{\text {anion }}\right)$. (HOSt: hydroxystyrene, tBOCSt: tert-butoxycarbonyloxystyrene, PAG: triphenylsulfonium triflate)

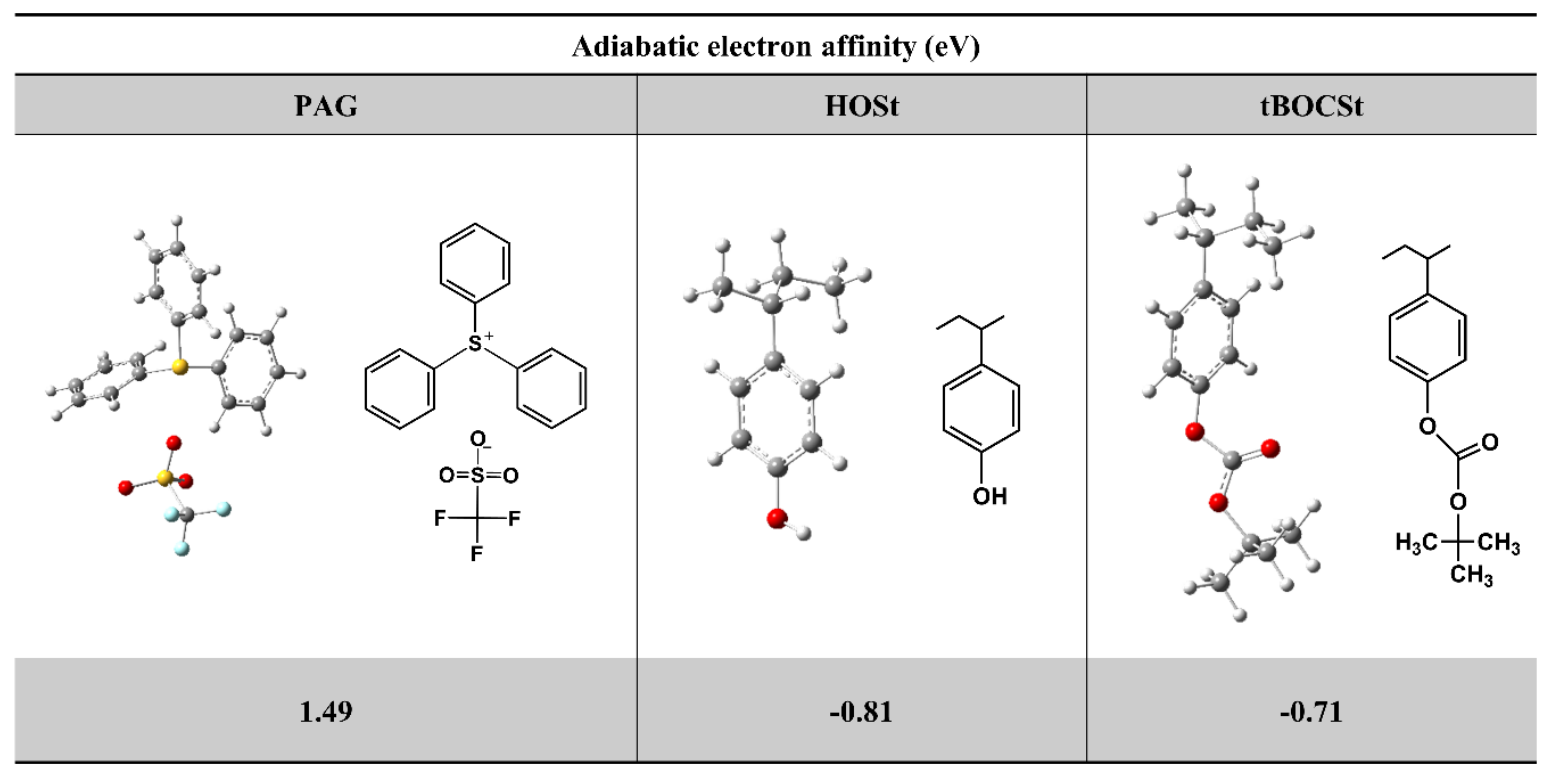

Table S2. Information of the AIMD unit cells of the neat polymeric pendant group and water-mixed system (see molecular configuration in Figure S9).

\begin{tabular}{ccc}
\hline Unit cell & No. of constituents & Density $(\mathrm{g} / \mathrm{cm} 3)$ \\
\hline HOSt & $\begin{array}{c}3 \text { HOSt dimers } \\
(3 \mathrm{~S} \text {-beads })\end{array}$ & 0.966 \\
tBOCSt & $\begin{array}{c}3 \text { tBOCSt trimers } \\
(3 \mathrm{I} \text {-beads })\end{array}$ & 0.994 \\
Water & $\begin{array}{c}75 \mathrm{H}_{2} \mathrm{O} \\
(3 \mathrm{~W} \text {-beads })\end{array}$ & 1.016 \\
HOSt + Water & $\begin{array}{c}1 \mathrm{HOSt} \text { trimer }+75 \mathrm{H}_{2} \mathrm{O} \\
(1 \mathrm{~S}-\text { bead }+3 \mathrm{~W} \text {-beads })\end{array}$ & 0.977 \\
\hline tBOCSt + Water & $\begin{array}{c}1 \text { tBOCSt dimer }+75 \mathrm{H}_{2} \mathrm{O} \\
(1 \mathrm{I} \text {-bead }+3 \text { W-beads })\end{array}$ & 0.973 \\
\hline
\end{tabular}


Table S3. Solubility parameter $(\delta)$ of pure water and HOSt system according to various energy functional.

\begin{tabular}{c|cc}
\hline \multirow{2}{*}{ Functional } & \multicolumn{2}{|c}{ Solubility parameter $\left(\left(\mathrm{J} / \mathrm{cm}^{3}\right)^{1 / 2}\right)$} \\
\cline { 2 - 3 } & Water & HOSt \\
\hline PBE & 44.56 & 7.20 \\
optB88-vdW & 55.43 & 25.11 \\
optPBE-vdW & 51.14 & 23.00 \\
vdW-DF2 & 48.84 & 19.80 \\
\hline DFT-D2 & 50.51 & 18.77 \\
\hline expt. & $47.82^{[\mathrm{S} 22]}$ & $19.43-24.54^{[\mathrm{S} 23, \mathrm{~S} 24]}$ \\
\hline
\end{tabular}

Table S4. Cohesive energy density $\left(E_{c o h} / V_{m}\right)$ of pure- and blended system (see molecular structure of the unit cell in Figure S9 and Table S2).

\begin{tabular}{c|ccccc}
\hline & HOSt & tBOCSt & Water & HOSt + Water & tBOCSt + Water \\
$\begin{array}{c}\text { Cohesive energy } \\
\text { density }\left(\mathrm{J} / \mathrm{cm}^{3}\right)\end{array}$ & 393.23 & 339.35 & 2385.54 & 1856.49 & 1724.67 \\
\hline
\end{tabular}

Table S5. Modulation of critical dissolution time for pattern fabrication ( $50 \%$ of polymer loss in PR matrix). $\tau$ is a reduced DPD time step of 0.01 .

DPD simulation time $\left(\times 10^{4} \tau\right)$

\begin{tabular}{|c|c|c|c|c|c|}
\hline Neat-2 ${ }^{a}$ & Neat5 ${ }^{a}$ & Neat-10 ${ }^{a}$ & Neat-20 a & Hybrid-2 ${ }^{b}$ & Hybrid-5 \\
\hline $1.92-3.24$ & $1.98-3.84$ & $2.52-4.68$ & $2.58-6.06$ & $2.10-3.66$ & $2.28-3.30$ \\
\hline
\end{tabular}

${ }^{\text {a }}$ Positive PR with $2.8-20.8 \mathrm{~kg} / \mathrm{mol}$ of $M_{n}{ }^{\mathrm{b}}$ Hybrid PR, which is the product of crosslinking reaction for Neat-2 and Neat-5, individually. 
Table S6. Activation energy $(\Delta E)$ of crosslinking reaction along $\mathrm{O}_{\mathrm{tBOCSt} .3}$ path according to various energy functional/orbital basis. (see potential energy surface in Figure S14c)

\begin{tabular}{c|ccccc}
\hline$\Delta E(\mathrm{eV})$ & $\mathrm{CCSD}(\mathrm{T})$ & B3LYP & APFD & M062X & TPSSh \\
\hline $6-311+\mathrm{G}(\mathrm{d}, \mathrm{p})$ & 1.32 & 1.64 & 1.34 & 1.52 & 1.52 \\
$6-311+\mathrm{G}(2 \mathrm{~d}, \mathrm{p})$ & & 1.65 & 1.35 & 1.54 & 1.54 \\
$6-311++\mathrm{G}(\mathrm{d}, \mathrm{p})$ & & 1.64 & 1.34 & 1.52 & 1.53 \\
$6-311++\mathrm{G}(2 \mathrm{~d}, \mathrm{p})$ & & 1.65 & 1.35 & 1.54 & 1.54 \\
\hline
\end{tabular}

\section{- References}

(S1) Groot, R. D.; Warren, P. B. Dissipative particle dynamics: Bridging the gap between atomistic and mesoscopic simulation. J. Chem. Phys. 1997, 107, 4423-4435.

(S2) Kresse, G.; Hafner, J. Ab-initio molecular-dynamics for open-shell transition-metals. Phys. Rev. B 1993, 48, $13115-13118$.

(S3) Kresse, G.; Furthmuller, J. Efficient iterative schemes for ab initio total-energy calculations using a planewave basis set. Phys. Rev. B 1996, 54, 11169-11186.

(S4) Blochl, P. E. Projector augmented-wave method. Phys. Rev. B 1994, 50, 17953-17979.

(S5) Kresse, G.; Joubert, D. From ultrasoft pseudopotentials to the projector augmented-wave method. Phys. Rev. B 1999, 59, 1758-1775.

(S6) Perdew, J. P.; Burke, K.; Ernzerhof, M. Generalized gradient approximation made simple.

Phys. Rev. Lett. 1996, 77, 3865-3868.

(S7) Ernzerhof, M.; Scuseria, G. E. Assessment of the Perdew-Burke-Ernzerhof exchange-correlation functional. J. Chem. Phys. 1999, 110, 5029-5036.

(S8) Thonhauser, T.; Cooper, V. R.; Li, S.; Puzder, A.; Hyldgaard, P.; Langreth, D. C. Van der Waals density functional: Self-consistent potential and the nature of the van der Waals bond. Phys. Rev. B 2007, 76, 125112-1125112-11. 
(S9) Chen, L.; Batra, R.; Ranganathan, R.; Sotzing, G.; Cao, Y.; Ramprasad, R. Electronic Structure of Polymer Dielectrics: The Role of Chemical and Morphological Complexity. Chem. Mater. 2018, 30, 7699-7706.

(S10) Filot, I. A. W.; Palmans, A. R. A.; Hillbers, P. A. J.; Hensen, E. J. M.; Greef, T. F. A.; Pidko, E. A. The origin of isotope-induced helical-sense bias in supramolecular polymers of benzene-1,3,5-tricarboxamides. Phys. Chem. Chem. Phys. 2012, 14, 13997-14002.

(S11) Kharche, N.; Hybertsen, M. S.; Muckerman, J. T. Phys. Chem. Chem. Phys. 2014, 16, 12057-12066.

(S12) Theodorou, D. N.; Suter, U. W. Detailed Molecular Structure of a Vinyl Polymer Glass. Macromolecules 1985, 18, 1467-1478.

(S13) Klimeš, J.; Bowler, D. R.; Michaelides, A. J. Phys. Condens. Matt. 2010, 22, 022201.

(S14) Maiti, A.; McGrother, S. Bead-bead interaction parameters in dissipative particle dynamics: Relation to bead-size, solubility parameter, and surface tension. J. Chem. Phys. 2004, 120, 1594-1601.

(S15) Hu, C.; Lu, T.; Guo, H. Mesoscale modeling of sulfonated polyimides copolymer membranes: Effect of sequence distributions. J. Membrane. Sci. 2018, 564, 146-158.

(S16) Cao, X.; Xu, G.; Li, Y.; Zhang, Z. Aggregation of Poly(ethylene oxide)-Poly(propylene oxide) Block Copolymers in Aqueous Solution: DPD Simulation Study. J. Phys. Chem. A 2005, 109, 10418-10423.

(S17) Soto-Figueroa, C.; Rodriguez-Hidalgo, M. R.; Vicente, L. Dissipative particle dynamics simulation of the micellization-demicellization process and micellar shuttle of a diblock copolymer in a biphasic system (water/ionic-liquid). Soft Matter 2012, 8, 1871-1877.

(S18) Kim, M.; Moon, J.; Choi, J.; Park, S.; Lee, B.; Cho, M. Multiscale Simulation Approach on Sub-10 nm Extreme Ultraviolet Photoresist Patterning: Insights from Nanoscale heterogeneity of Polymer. Macromolecules 2018, 51, 6922-6935.

(S19) Liu, J.; He, X.; Zhang, J. Z. H.; Qi, L.-W. Hydrogen-bond structure dynamics in bulk water: insights from ab initio simulations with coupled cluster theory. Chem. Sci. 2018, 9, 2065-2073.

(S20) Luzar, A.; Chandler, D. Effect of Environment on Hydrogen Bond Dynamics in Liquid Water. Phys. Rev. Lett. 1996, 76, 928-931.

(S21) Frisch, M. J.; et al. Gaussian 09, Revision E.01; Gaussian Inc.: Wallingford, CT, 2009.

(S22) Hansen, C. M. Hansen Solubility Parameters: A User's Handbook, $2^{\text {nd }}$ edition; CRC Press, 2007, p 56.

(S23) Suh, K. W.; Clarke, D. H. Cohesive energy densities of polymers from turbidimetric titrations. J. Polym. Sci. A 1967, 5, 1671-1681.

(S24) Arichi, S.; Himuro, S. Solubility parameters of poly(4-acetoxystyrene) and poly(4-hydroxystyrene). Polymer 1989, 30, 686-692. 